\title{
Effect of Ion Beam Assisted Deposition technology on the cathode of solar cells
}

\author{
M.Chakaroun ${ }^{1, *}$, A. Saleh ${ }^{1}$, and M. El-Khatib ${ }^{1}$ \\ ${ }^{1}$ Lebanese University - Faculty of Technology - B. P.: 813 SAIDA, Lebanon
}

\begin{abstract}
We realized organic solar cells on ITO anode based on small molecular materials (CUPC:C60) to be easy to fabricate, cost price, production on large surfaces, efficiency, flexibility and large market of solar panels, but the organic materials are limited by their lifetime. Then, on the ITO we deposited the organic materials by using the vacuum coevaporation deposition. Cathode is a silver layer to protect the organic layer from the humidity. The penetrations of humidity from the cathode to the organic layer give to organic electronic components a short lifetime, and limit the fabrication of organic solar panels. In order to optimize the lifetime of organic solar cells, we use in this study the IBAD's technology to deposit the cathode instead of vacuum co-evaporation deposition. The goal of this technology is to reduce the permeation of $\mathrm{H} 2 \mathrm{O}$ and $\mathrm{O} 2$ from the cathode to the organic layer, by using the argon ions to assist the aluminium deposition of cathode. We realized two series of cells under vacuum and do not exposed to the air. The first, with cathode deposit by the vacuum co-evaporate deposition, but the second we use the IBAD technology to deposit the cathode $(60 \mathrm{~nm}$ unassisted and $40 \mathrm{~nm}$ deposited with ionic assistance), after we compare their lifetime in the ambient air and under continuous illumination.
\end{abstract}

\section{Introduction}

In global market of solar system and the most widely used inorganic semiconductor (silicon), their efficiency is blocked by its mass production (with high process of energy and cost). However although, the organic electronic components are always more widely used because they offer numerous advantages as regards costs in terms of production, output and flexibility. Among the organic electronic components we can find organic LEDs and organic solar cells.

To describe an organic solar cell, including a substrate, an organic layer is inserted between a lower electrode and an upper electrode, also, in contact with the substrate, and which is able to emit radiation through at least one of the electrodes when current is supplied through the active layer by the chosen electrode. However, the scattering into the organic layer of some elements existing in the air, such as oxygen or water vapour, results in the deterioration of the active layer which limits the lifetime of the organic semiconductor, than the solar cell and the solar panels. This problem is formed by the diffusion

* Corresponding author: mohamad.chakaroun@edu.lb.com 
of water and oxygen from the ambient air to the cells in the time of utilization formed some dark spots in cathode of organic solar cells, than ruin of organic solar system.

In order to solve such a problem, we have insert a layer of aluminium bombarded by the ions on the top of the cathode to crystallize it by using technology of ion beam assisted deposition [1, 2 and 3]. We use the process of IBAD to deposit our aluminium cathode. In this paper, we present characterizations and lifetime measurements of organic solar cells showing the IBAD effects on the cathode, to product the organic layer from the penetration of $\mathrm{H}_{2} \mathrm{O}, \mathrm{O} 2$ or the other elements existing in the air.

\section{Experimental}

\subsection{Realisation of organic solar cells}

In the first time, we gravure the layer of ITO (indium tin oxide) deposited on the glass substrate $(12 \mathrm{~mm} \times 12 \mathrm{~mm})$ by Visionteck with the following properties:

- Thickness $150 \mathrm{~nm}$

- Transmittance at $550 \mathrm{~nm}$ is close to $89 \%$

- Sheet resistance is $1212 \Omega / \square$

Second we clean the substrate by using ultrasonic cleaner in acetone, de-ionised water, isopropylic alcohol finally de-ionised for 10 minutes for each solution.

Third, we use the spin coating to deposit $30 \mathrm{~nm}$ from PEDOT-PSS (Poly(3,4ethylenedioxythiophene) - Poly(styrenesulfonate)) on the ITO cathode. This layer is used as a hole transport and barrier layer to block the diffusion of $\mathrm{O} 2$ from ITO and active layer [4, 5].

Fourth, organic layer in composed by $25 \mathrm{~nm}$ of CuPc (Copper phthalocyanine), $40 \mathrm{~nm}$ of C60 (Fullerene) and $2.5 \mathrm{~nm}$ of BCP (Bathocuproine). This organics material was tacked from Aldrish and H. W. Sands. We use the co-evaporation (by Joule effect) [6] built in house to deposit on the top of ITO/PEDOT-PSS this organic materials under vacuum (5.10-6 mbar) and thermal temperature to sublime at $215^{\circ} \mathrm{C}$ for $\mathrm{CuPc}$, at $250{ }^{\circ} \mathrm{C}$ for $\mathrm{C} 60$ and at $300{ }^{\circ} \mathrm{C}$ for BCP. These temperatures were monitored by a Eurotherm 2700 process according to the quartz monitor sensibility of $0.5 \AA \AA s-1$. We are used this quartz to control the speed of deposition to $\approx 4.8 \mathrm{~nm} / \mathrm{min}$ for $\mathrm{CuPC}, \approx 6 \mathrm{~nm} / \mathrm{min}$ for $\mathrm{C} 60$ and $\approx 120 \mathrm{~nm} / \mathrm{min}$ for $\mathrm{BCP}$. We insert the buffering layer of BCP between the organic layer and the cathode to stop the diffusion of aluminium prior their deposition to the layer $\mathrm{CuPc} / \mathrm{C} 60$ and to improve the interface organic /aluminium [7].

Finally, on the BCP layer we deposit the cathode with $100 \mathrm{~nm}$ of thickness and $25 \mathrm{~mm}^{2}$ of area, by using the vacuum co-evaporate deposition for the first series of cells and IBAD for the second series [8]

\subsection{Configuration of lon beam assisted deposition}

IBAD technology consists to merge simultaneously film deposition by co-evaporator and bombardment on one side with an independently controlled ion beam on the other.

IBAD it is a chamber of stainless steel with a volume of 591 (fig. 1), related to two pumps of a turbo-molecular pump Alcatel ATP 400:

- The primary pump to obtain a vacuum limited of about $5.10^{-7} \mathrm{mbar}$.

- The secondary pump to realize a pressure of $2.10^{-6}$ before the deposition.

The ion source is a Kaufman-type to assist the metal deposition with an ion beam. The experimental setup is broadly divided into three parts: 
1) An ion source (fabricated by Veeco): with ion beam energy between $50 \mathrm{ev}$ and $1 \mathrm{ev}$, located at $40 \mathrm{~cm}$ from the substrate with a $45^{\circ}$ inclination angle.

2) A source of aluminium evaporation is composed by a resistance to heat the aluminium powder placed in an alumina box (Midwest Tungsten) related to heated sources.

3) A substrate holder disposed at the two sources: the picoampermeter (Keithley) delivers a current density of ion beam by using Faraday cup (between 100 and $80000 \mathrm{~nm} / \mathrm{cm} 2$ and it is uniform on $12 \mathrm{~cm}^{2}$ area).

We use two masks to block the ion beam during the unassisted deposition and quartz to control the thickness of the cathode to obtain $100 \mathrm{~nm}$ (60nm unassisted $+40 \mathrm{~nm}$ assisted).

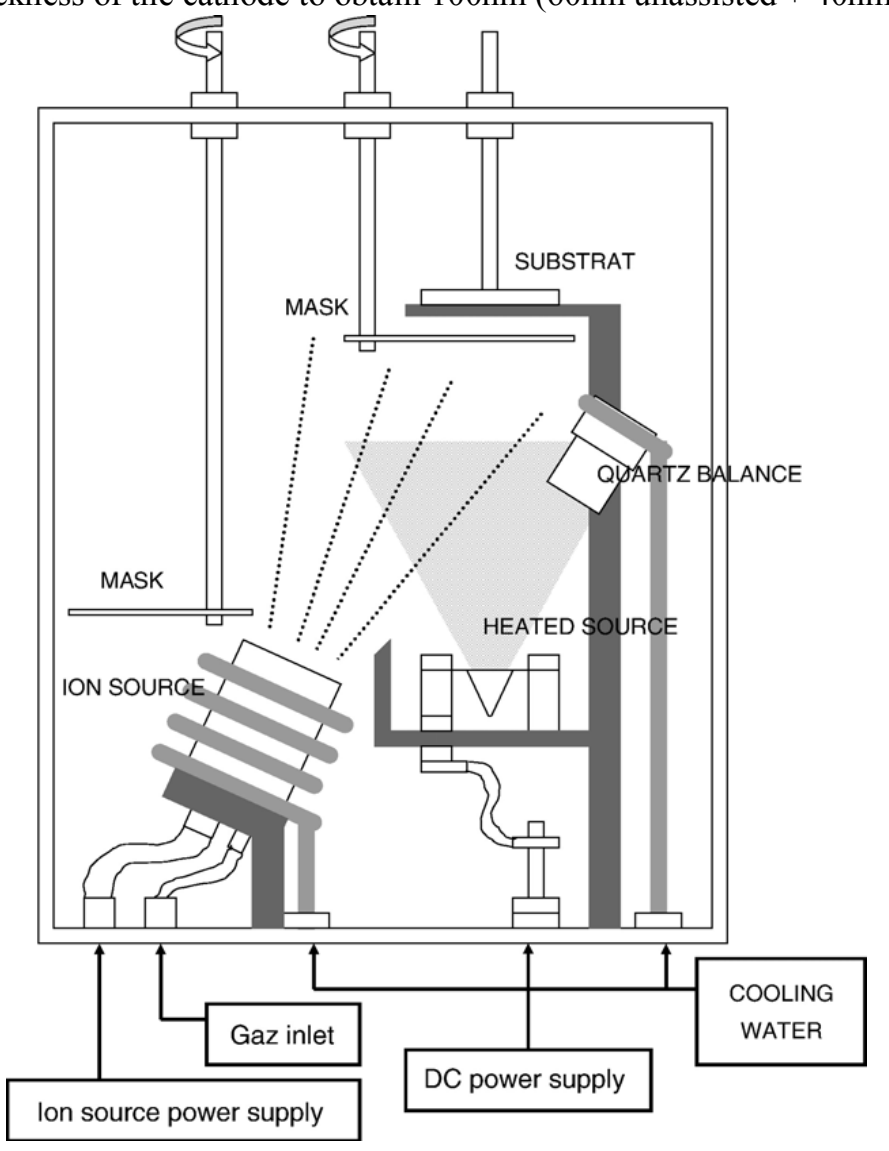

Fig. 1. Simplified diagram of the IBAD chamber

\section{Results and discussion}

The encapsulation of photovoltaic cells limits the diffusion of humidity ( $\mathrm{H} 2 \mathrm{O}$ and $\mathrm{O} 2$ ) through the side walls of the active layer. But, in this study, we will solve an important part of the diffusion through the pores of the cathode.

A previous study [8] shows that IBAD assisted metallization improves the lifetime of OLEDs. The collisions of the Ar+ ions (argon) with the aluminium atoms during the metallization allow the latter to acquire kinetic energy. The collisions make it possible to 
densify the cathode, which reduces the formation of porosities and subsequently the penetration of the $\mathrm{O} 2$ and $\mathrm{H} 2 \mathrm{O}$ molecules by these porosities.

The two cells were produced with the same conditions for the deposition of organic layers. The two cells have an area of $25 \mathrm{~mm}^{2}$ and the structure of the active layer is ITO / PEDOT: Pss $(30 \mathrm{~nm}) / \mathrm{CuPc}(25 \mathrm{~nm}) / \mathrm{C} 60(40 \mathrm{~nm}) / \mathrm{BCP}(2.5 \mathrm{~nm}) / \mathrm{Al}(100 \mathrm{~nm})$. The first cell is metallized in the vacuum co-evaporation deposition (10-6 mbar) and the second cell is metallized in the d IBAD, with two layers of aluminium: $60 \mathrm{~nm}$ unassisted and $40 \mathrm{~nm}$ deposited with ionic assistance. We are used the ion beam $\mathrm{Ar}+$ with the following parameters:

- $\quad$ Ion energy $=600 \mathrm{eV}$.

- $23000 \mathrm{nA} / \mathrm{cm}^{2}$ in current density.

- Beam incidence angle $=45^{\circ}$

\subsection{Characteristic $J(V)$ in glove box}

Fig. 2 shows an improvement in the structure of $\mathrm{J}(\mathrm{V})$ characteristic, which has a "more ideal" curve for the assisted cathode. The photovoltaic parameters of these cells, extracted from the $\mathrm{J}(\mathrm{V})$ curves under illumination of $\mathrm{AM} 1.5$ of $100 \mathrm{~mW} / \mathrm{cm}^{2}$ in a controlled atmosphere (without oxygen and water), are reported in the following table 1:

Table 1. Photovoltaic parameters extracted from $\mathrm{J}(\mathrm{V})$ curves of devices under illumination

\begin{tabular}{|c|c|c|c|c|c|c|}
\hline & $\eta \mathrm{e}(\%)$ & FF & $\operatorname{Vco}(V)$ & $\begin{array}{c}\mathbf{J c c} \\
\left(\mathbf{m A} / \mathbf{c m}^{2}\right)\end{array}$ & $\operatorname{Rs}(\Omega)$ & $\operatorname{Rsh}(\Omega)$ \\
\hline $\begin{array}{c}\text { Metallization in vacuum } \\
\text { evaporation }\end{array}$ & 0.72 & 0.541 & 0.45 & 2.794 & 114 & 5838 \\
\hline Metallization in IBAD & 1.254 & 0.53 & 0.44 & 5.28 & 91 & 3791 \\
\hline
\end{tabular}

The ionic assistance of the aluminium improves the power efficiency $(\eta)$ of the organic solar cell from 0.72 to $1.3 \%$. This increasing of efficiency is due to amelioration in the fill factor (FF) and the short circuit current density (Jcc). The fill factor reaches in particular the value 0.53 comes from the decreasing of the series resistance ( $\mathrm{Rs} \approx 91 \Omega$ ) and the increasing of the shunt resistance $(\mathrm{Rsh} \approx 3.8 \mathrm{~K} \Omega$ ). It seems that the improvement of photovoltaic parameters due to the penetration of the $\mathrm{Ar}+$ ions into the active layer during the ionic assistance. The obtaining of a very high current density when the cathode is assisted has already been reported in a previous study [9]. The densification of the aluminium layer by ionic assistance makes it possible to improve the interface active layer/cathode, which does not appear to be the case for this cell which has a higher series resistance than that of the non-assisted cell. 


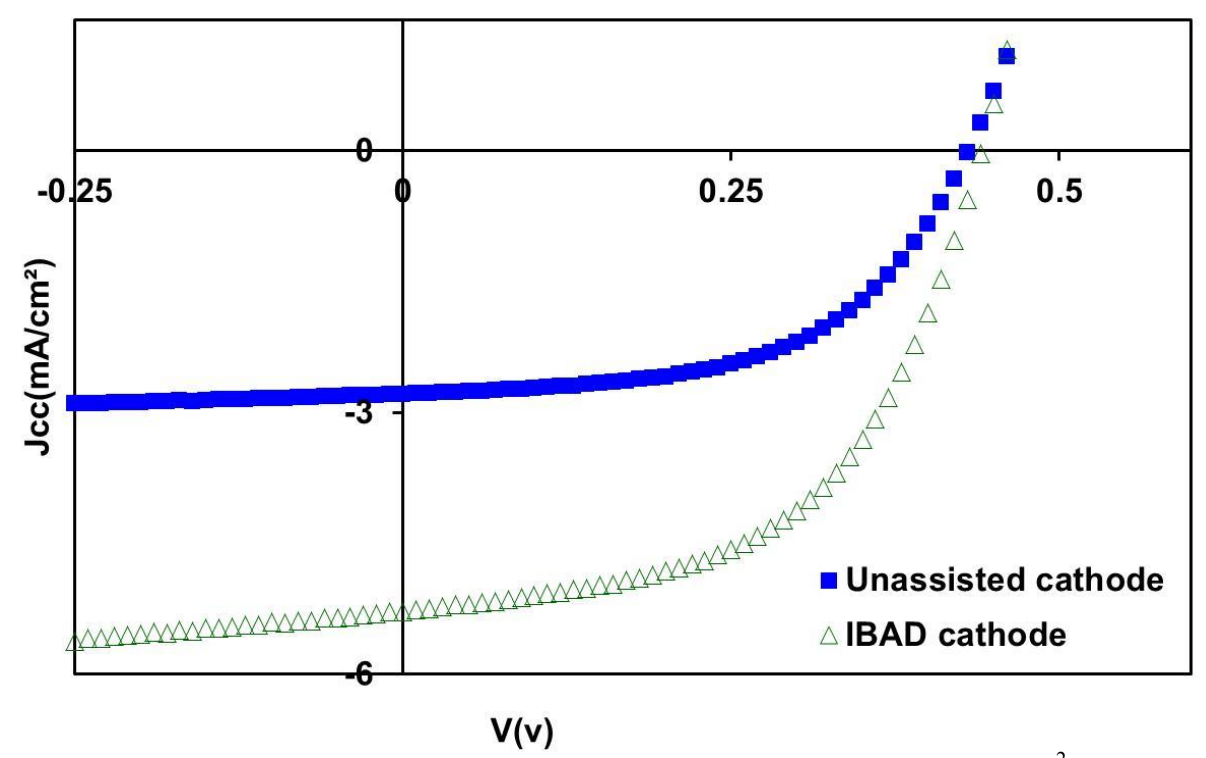

Fig. 2. J(V) Characteristics of photovoltaic cells under illumination at $100 \mathrm{~mW} / \mathrm{cm}^{2}$ of devices.

Indeed, the energy of the Ar+ ions was relatively high $(600 \mathrm{eV})$, which increases the path of the ions in the treated layer. Although this energy modelling of ionic assistance by the software SRIM2003 shows that the argon ions and the reversing atoms resulting from the collisions during the assistance are not supposed to penetrate more than 4 or $5 \mathrm{~nm}$ in the layer of aluminium [10], the unassisted layer of aluminium must be large enough, as the experiments on OLEDs are shown. In particular, for small thicknesses of metallization, the growth of the aluminium layer has a pick structure which can be responsible for the ionization with relatively large paths. To avoid this problem we have increased the thickness of the virgin aluminium of $60 \mathrm{~nm}$ at $80 \mathrm{~nm}$, decreased the thickness of the assisted layer from $40 \mathrm{~nm}$ to $20 \mathrm{~nm}$ and reduce the energy of the $\mathrm{Ar}+$ ions from $600 \mathrm{eV}$ to $100 \mathrm{eV}$.

\subsection{Lifetime measurements}

We measured the evolution of the different parameters of photovoltaic cells as a function of time in open air and under continuous illumination. Among these parameters, the most useful for our study are the series resistance, the conversion efficiency and the short circuit current density as they better reflect of degradation or the good functioning of the devices. Fig. 4 shows the evolution of the $\mathrm{J}(\mathrm{V})$ characteristics of these solar cells (with / without ionic assistance) over a period of 16. The photovoltaic parameters from the J (V) characteristics are shown in Fig. 5. 


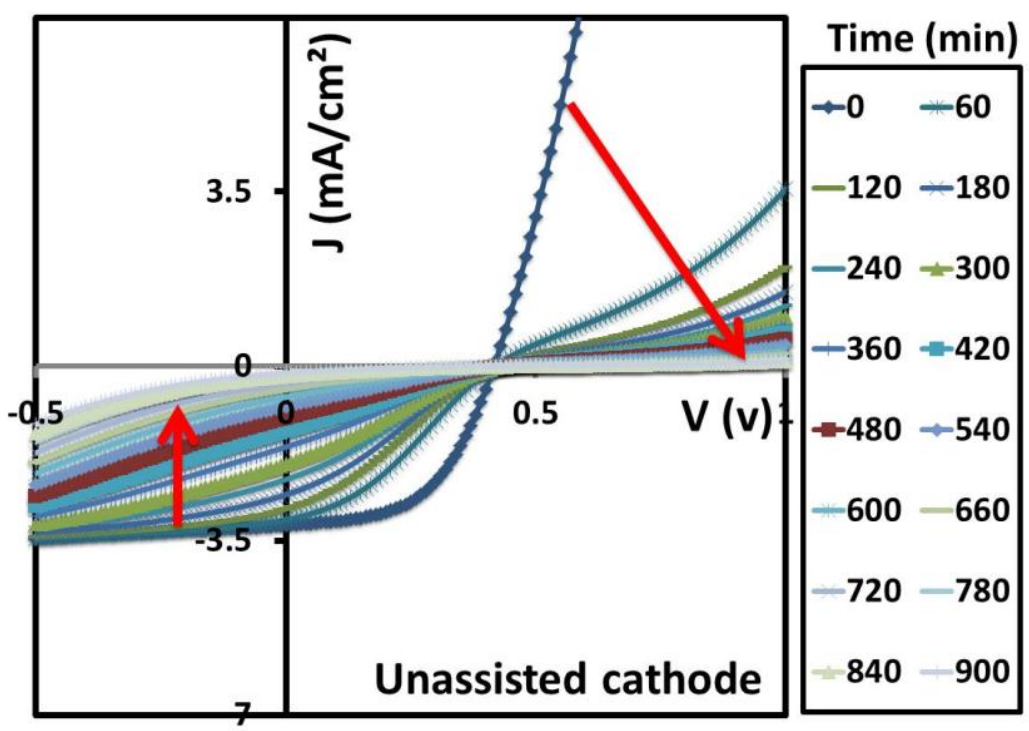

Fig. 3. Evolution of the characteristic $J=f(V)$ as a function of time of cells with unassisted cathode.

In the case of an unassisted cathode, the characteristic J(V) (fig. 3) changes very quickly as a function of time. This variation caused by the decreasing of FF which is manifested by the progressive appearance of an "anti-diode" effect on the $\mathrm{J}(\mathrm{V})$ characteristics.

In the case of an assisted cathode, the characteristic J(V) (Fig. 4) degrades much more slowly as a function of time. The effect of "anti- diode" is noticeable after eight hours instead of $10 \mathrm{~min}$ in the case of an unassisted cathode.

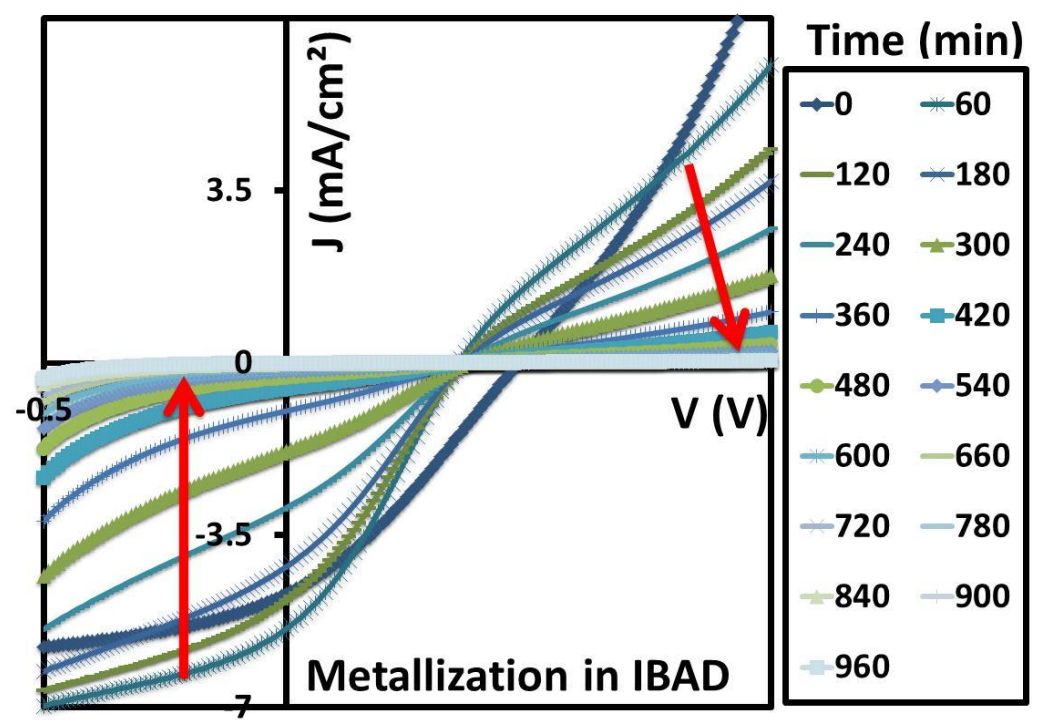

Fig. 4. Evolution of the characteristic $J=f(V)$ as a function of time of cells with cathode realised by IBAD. 
In presence of the humidity in the ambient air, the molecules of $\mathrm{O} 2$ and $\mathrm{H} 2 \mathrm{O}$ defuse from the unassisted cathode to the BCP layer located just below, which crystallizes this layer [11], then facilitates the diffusion of $\mathrm{O} 2$ and $\mathrm{H} 2 \mathrm{O}$ to the $\mathrm{C} 60$ layer. The main role of $\mathrm{C} 60$ layer is to transport the electron, but in this case the cell become quickly becomes insulating, which modifies the characteristic J (V).

The current density Jcc drops rapidly in the case of un-assisted cell (Fig. 5.-b-). This phenomenon is due to the penetration of oxygen and water into the C60 layer, which creates a large number of obstacles for photo-generated electrons. As a result, the number of collected charges is decreased. In the other case, the densification of cathode by the IBAD decrease the number of obstacles generated by the diffusion of humidity; Jcc attenuation aver time is much slower.
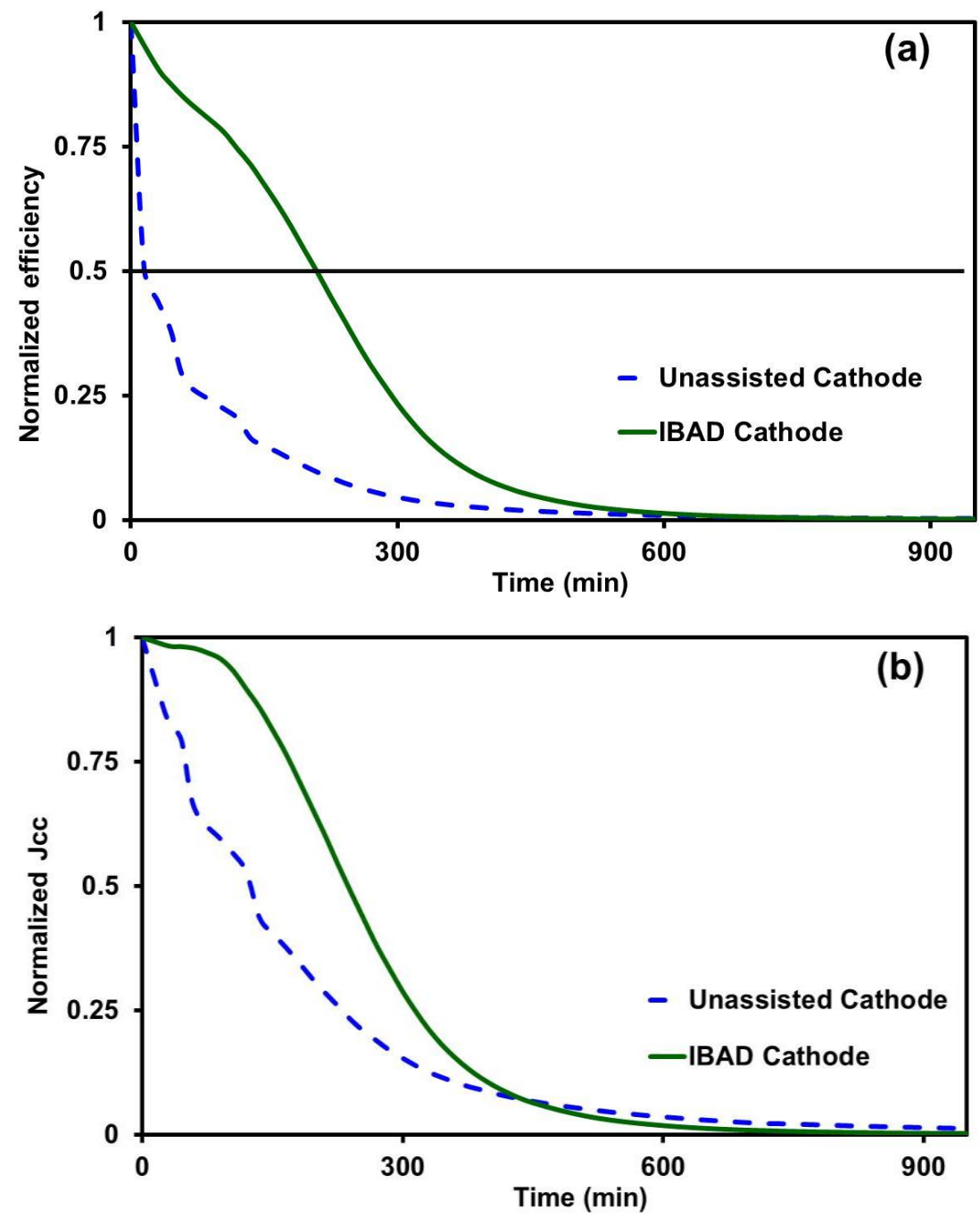

Fig. 5. (a) Normalized power efficiency (b) Normalized current density (Jcc) of two cells versus time. The first cell cathode metalized in vacuum and the second metalized in IBAD 
Fig. 5-a- shows the normalized values of the efficiency versus time for the two cells (time required for the efficiency to fall by half of its initial value) are $15 \mathrm{~min}$ and $210 \mathrm{~min}$ respectively. Thus the cell (with $40 \mathrm{~nm}$ assisted $\mathrm{Al}$ ) increases the lifetime 14 times relative to the reference.. The Aluminium in the un-assisted cell protect the active layer only 15 minutes, while assisted cathode of aluminium protect the device higher than 5 hours. For the un-assisted device, the cathode was totally destroyed by the "dark spot" phenomenon, but the cathode of the assisted device stayed uniform. So, the "dark spot" allows to water and oxygen to destroy the active layer (CuPc-C60), than increase the speed of degradation of CuPc-C60. Finally, the IBAD densifying the deposited layer of aluminium and decrease the lifetime.

The beneficial effect of cathode ion beam assistance appears to be predominant during the first 5 hours of operation of the cell as shown in Fig. 5. This is to be compared with the mechanism of degradation which we have assumed:

- The degradation of the cathode takes place essentially during the first hours of illumination.

- The degradation of the active layer in its volume by water and oxygen

\section{Conclusion}

In order to improve the cathode layer characteristics, we have realized this layer with the ion beam assisted deposition process. The aim of this process is to densify the layer and then reduce the permeation of $\mathrm{H} 2 \mathrm{O}$ and $\mathrm{O} 2$. We have used argon ions to assist the silver deposition .In this study we tried a few tests of cathode depositions assisted by ion beams (60 nm unassisted and $40 \mathrm{~nm}$ deposited with ionic assistance). This technique makes it possible to densify the aluminium layer and to reduce the dark spots by which oxygen and water diffuses to active layer (CuPc-C60). Using this technique alone increases the lifetime ( $50 \%$ of the initial value of efficiency) of our reference cell by 14 times from 14 minutes for the cell with unassisted cathode to 210 minutes to the cell with an assisted cathode, by combining the deposition of the cathode with IBAD.

Equations should be centred and should be numbered with the number on the right-hand side.

\section{Acknowledgement}

The authors thank research institute Xlim-France for funding this study and Faculty of Technology in Lebanese University.

\section{References}

1. F.A. Smidt, "Use of ion beam assisted deposition to modify the microstructure and properties of thin films", Int. Mater. Rev. 35 (1990) 61.

2. R. Antony, A. Moliton, B. Ratier, "Effect of various ions on organic light-emitting diodes obtained by ion-beam-assisted deposition”, Appl. Phys., B 71, 2000, pp. 33-41.

3. R. Antony, A. Moliton, B. Lucas, "organic light-cmitting devices obtained with helium-ion-beam-assisted depositin process", Appl. Phys., A 70, 2000, pp. 185.

4. P. Peumans, S.R. Forrest, "Very-high-efficiency double-heterostructure copper photovoltaic cells", Appl. Phys. Lett. 79, 2001, pp. 126 
5. P. Peumans, S. Uchida, S.R. Forrest, "Efficient bulk heterojunction photovoltaic cells using small-molecular-weight organic thin films", Nature 425, 2003, pp. 158.

6. J. Xue, S. Uchida, B.P. Rand, S.R. Forrest, Appl. Phys. Lett. 84, "4.2\% efficient organic photovoltaic cells with low series resistances”, 2004, pp. 3013-3015.

7. D. Gebeyehu, B. Maennig, J. Drechsel, K. Leo, M. Pfeiffer, "Bulk-heterojunction photovoltaic devices based on donor-acceptor organic small molecule blends", Sol. Energ. Mater. Sol. Cells 79, 2003, 81-92.

8. M. Chakaroun, R. Antony, P. Taillepierre, A. Moliton, "Lifetime obtained by ion beam assisted deposition”, Materials Science and Engineering C 27, 2007, pp. 1043-1045.

9. R. RADBEH, Université de LIMOGES, Thèse numéro 71-2008 .

10. Chakaroun M, Ratier B, Moliton A, IECON 2006 - 32nd annual conferene on IEEE industrial electronics, Vols 1-11 Book Series: IEEE Industrial Electronics Society, 2006, pp. 5398-5402.

11. J.Felton, “Thinner lighter better brighter", Today's chemist at work 10 (2001), 30. 